\title{
Factors influencing quality of life in patients followed in the neurosonology laboratory for carotid stenosis
}

\author{
Táňa Fadrná ${ }^{1}$ Zdeňka Mikšová', Roman Herzig ${ }^{3}$, Kateřina Langová ${ }^{24}$, Libor Ličman ${ }^{4}$ and David Školoudík ${ }^{2^{*}}$ (D)
}

\begin{abstract}
Background: Quality of life $(\mathrm{Q} O \mathrm{~L})$ is one of the main endpoints in stroke prevention or acute stroke treatment studies. The aim of the current study was to identify risk factors affecting the QoL of patients with carotid stenosis in stroke prevention.

Methods: Self-sufficient patients (50-80 years of age) with $\geq 20 \%$ carotid artery stenosis followed in the neurosonology laboratory, and without any severe illnesses within the last 12 months, dementia, or psychiatric disorders were selected for the study after signing informed consent. Patients completed two standardized QoL questionnaires (WHOQoL-BREF and EQ-5D-3 L) and a visual pain scale, provided covariate variables (medication, age, gender, education, and social situation), and the blood pressure and body mass indexes were recorded. Logistic regression (forward stepwise method) was used to identify factors affecting the individual domains of QoL questionnaires.

Results: Of the 584 consecutive patients, 502 met the inclusion criteria and 344 completely filled both QoL questionnaires (164 men; mean age, $69.7 \pm 7.8$ years). An independent predictor of worse QoL in all domains was pain. Independent factors decreasing the QoL were lower level of education and blood pressure in the physical health domain, female gender in the psychological domain, and male gender in the social relationships domain. Independent factors decreasing satisfaction with health status were female gender and higher blood pressure. Factors negatively influencing the satisfaction with the QoL were living alone, lower level of education, and higher diastolic blood pressure (WHOQoL-BREF). Factors negatively influencing mobility were age, male gender, living alone, lower level of education, and higher body mass index (EQ-5D-3 L; $p<0.05$ in all cases).
\end{abstract}

Conclusions: Pain, blood pressure, body mass index, education, living alone, gender, and age were associated with the QoL in patients with carotid stenosis.

Trial registration: ClinicalTrials.gov, NCT02360137. Registered on 26 January 2015.

Keywords: Quality of life, Questionnaire, Stroke, Risk factors

\section{Background}

Atherosclerotic disease is the leading cause of death and morbidity in developed countries in the past decades [1]. The carotid bifurcation and internal carotid arteries are sites with a very high predilection for the formation of atherosclerotic plaques [2]. Atherosclerotic carotid

\footnotetext{
* Correspondence: skoloudik@hotmail.com

${ }^{2}$ Center for Science and Research, Department of Nursing, Faculty of Health Sciences, Palacký University Olomouc, Hněvotínská 3, CZ-775 15 Olomouc, Czech Republic

Full list of author information is available at the end of the article
}

stenosis is a main cause of stroke [3] and, stroke is the second most common cause of death and the leading cause of disability worldwide $[4,5]$. In fact, about $20 \%$ of 15 million stroke patients worldwide are in need of medical care and rehabilitation procedures each year after suffering of stroke, and approximately 5.7 million patients die [6-8].

New treatment methods (i.e., intravenous thrombolysis, endovascular treatment, and neurointensive care) have led to a decrease in the number of stroke patients with permanent disability [9-12]. Nevertheless, only

(c) The Author(s). 2018 Open Access This article is distributed under the terms of the Creative Commons Attribution 4.0 International License (http://creativecommons.org/licenses/by/4.0/), which permits unrestricted use, distribution, and reproduction in any medium, provided you give appropriate credit to the original author(s) and the source, provide a link to the Creative Commons license, and indicate if changes were made. The Creative Commons Public Domain Dedication waiver (http://creativecommons.org/publicdomain/zero/1.0/) applies to the data made available in this article, unless otherwise stated. 
about $50 \%$ of patients reach full independency after stroke despite of new treatment use [10-12]. The persisting impairment in motor function is the main, but not the only, reason for dependency in activities of daily living among stroke patients [13, 14]. Post-stroke depression, cognitive impairment, urinary incontinence, and other non-motor function impairment are relatively frequent health problems after stroke, thus leading to a decrease in the quality of life (QoL) [13-15]. Thus, QoL has become one of the main endpoints in stroke prevention or acute stroke treatment studies and, evaluation of QoL has become the standard tool for evaluation of the effectiveness of prevention and acute treatment of stroke [16-18].

The prevalence of carotid stenosis is approximately $10 \%$ in subjects $>70$ years of age, the majority of whom are asymptomatic [19]; however, there are a lack of studies evaluating QoL in patients with carotid stenosis. Moreover, the majority of published studies have only included patients with carotid stenosis indicated for carotid revascularization, e.g., carotid endarterectomy or stenting [20-24]. A systematic review and meta-analysis of studies evaluating QoL after carotid revascularization showed that QoL did not change significantly in any domain in patients 1 year after carotid endarterectomy or stenting. Nevertheless, physical function, vitality, body pain, and social function domains were transiently worse 2 weeks after the procedure, and occurred more frequently after carotid endarterectomy than after carotid stenting [24]. Middleton et al. [25] showed that QoL of patients 3 months after carotid revascularization was better than QoL in the general population of patients with a previous history of stroke, but remained worse than in patients without a previous stroke.

Thus, one may hypothesize that risk factors and clinical consequences of atherosclerosis in patients with carotid stenosis may significantly influence the QoL. Identification of the factors influencing the QoL in a prevention of stroke is necessary for treatment optimization and to preserve QoL. The aim of the current study was to identify risk factors affecting the QoL of patients with carotid atherosclerotic stenosis in stroke prevention.

\section{Methods}

\section{Questionnaires}

A quantitative cross-sectional study with standardized QoL questionnaires (World Health Organization Quality of Life [short version] \{WHOQoL-BREF\} and three-Level EuroQol-5D [EQ-5D-3 L]) was conducted to identify the factors influencing QoL in patients with carotid atherosclerotic stenosis in stroke prevention including risk factors for atherosclerosis (age, gender, weight, height and body mass index, systolic and diastolic blood pressure, arterial hypertension, diabetes mellitus, hyperlipidemia, smoking and alcohol misuse), diseases caused by atherosclerosis (coronary heart disease, myocardial disease, atrial fibrillation and other heart disease, transient ischemic attack, stroke, and peripheral arterial disease), arterial interventions (carotid endarterectomy, coronary artery bypass graft, surgery for peripheral arterial disease, carotid artery stenting, coronary artery stenting, and stenting of other arteries), and other concomitant factors (pain, social situation, and education). For this purpose, one generic questionnaire (WHOQoL-BREF) and one generic questionnaire widely used in stroke patients (EQ-5D-3 L) were selected [26, 27]. The reason for using two different generic questionnaires was to compare the usability of both questionnaires for identifying risk factors influencing QoL.

The WHOQoL-BREF questionnaire included two questions assessing the individual's overall perception of QoL and the overall perception of their health, and 24 questions in four domains (physical health DOM1, psychological - DOM2, social relationships - DOM3, and environment - DOM4). Particular items were assessed using a five-point Likert scale [26]. The mean score of items within each domain was used to calculate the domain score. The mean score of the first two items (How would you rate your quality of life? - Q1, How satisfied are you with your health? - Q2) was calculated separately as defined in WHOQoL User Manual [28]. The official Czech version of the WHOQoL-BREF questionnaire was used with permission from The World Health Organization.

The second questionnaire was the generic questionnaire EQ-5D-3 L [27]. The reason for using this second generic questionnaire was that the second questionnaire has been frequently used in stroke patients and contains different domains in comparison with WHOQoL-BREF. The EQ-5D-3 L contains five domains (questions) involving QoL (mobility DOM1, self-care - DOM2, usual activities - DOM3, pain/discomfort - DOM4, and anxiety/depression DOM5). The respondents used a three-level evaluation of the health state description (no problems, some or moderate problems, and an inability to do/ extreme problems). The second part of the questionnaire was the visual analogue 100-point scale, which evaluated the current health status of the individual [29]. The official Czech version of the EQ-5D-3 L questionnaire was used with permission from The EuroQol Research Foundation. The three-level EQ$5 \mathrm{D}$ questionnaire, instead of the five-level questionnaire, was used due to the non-existence of an 
official Czech version of EQ-5D-5 L when the study was designed.

\section{Participants}

Participants from the observational stroke prevention study (ANTIQUE Trial, ClinicalTrials.gov Identifier: NCT02360137, registered on January 26, 2015) who were followed in the Neurosonology Laboratory were selected for participation in the study. The inclusion criteria were as follows: a) self-sufficiency with $0-2$ points on the modified Rankin scale (mRS); b) carotid atherosclerotic stenosis $\geq 20 \%$ using ECST study criteria [30]; c) $50-80$ years of age; $d$ ) and signed informed consent. The exclusion criteria were as follows: a) hospitalization for a severe illness, including stroke, during the last 12 months; b) dementia (Mini Mental State Examination $<20$ points; c) psychiatric disease, including depression (Beck depression Inventory $\geq 20$ points); d) severe visual or hearing impairment or other inability to complete the questionnaires based on the patient's judgement; e) terminal stage of the disease including active cancer with a life expectancy $<2$ years (according to the physician opinion); and f) living in a retirement home, nursing home, or hospital.

The entire study was conducted in accordance with the Helsinki Declaration of 1975, as revised in 2004 and 2008. The study was approved by the local Ethics Committee of the Faculty of Health Sciences, Palacký University Olomouc (No. UPOL-7279/1040-2015). All subjects provided written informed consent before enrollment.

\section{Clinical examination}

The neurologic and physical examinations, and duplex sonography of the cervical arteries were performed in all patients. The covariate variables (diseases, surgical procedures, medication, age, gender, level of education [primary, secondary, secondary with graduation, and tertiary], social situation [marital status, living alone, living with a partner or with family members], blood pressure, ten-level visual analogue pain scale, body mass index $[\mathrm{BMI}]$, sufficiency using $\mathrm{mRS}$, smoking, alcohol consumption [the usual daily dose of alcohol reported by the patient], and percent of carotid stenosis) were recorded. Data were collected from medical and selfreports of patients.

\section{Statistics}

Pre-study calculations (expected difference of 0.5 point in WHOQoL domain for the variable presented in $50 \%$ of subjects) showed that a minimum of 502 respondents were required to reach significant results for with an alpha value of 0.05 (two-tailed) and a beta value of 0.8 , assuming that $60 \%$ of subjects (301 respondents) will pass inclusion criteria and return completely filled questionnaires. Both questionnaires were evaluated as complete when $\leq 20 \%$ of items were missing. Covariate missing value did not exclude the patients from analysis, with the exception of logistic regression.

The normality of data distribution was checked using the Shapiro-Wilk test. All data except body height were not normally distributed. Demographic data are reported as the median, mean and standard deviation or number and percentage. Data from both questionnaires were processed as ordinal data with 5 (WHOQoL-BREF) or 3 (EQ-5D-3 L) values, except for the visual analogue scale in EQ-5D-3 L, in which data were processed as quantitative. Categorical variables in the two arms (completers and non-completers) were compared by Fisher's exact test. Continuous variables were compared by the Student's $t$ test for normally distributed values. The Mann-Whitney $U$ test (for variables with 2 groups) or Kruskal-Wallis test (for variables with more than 2 groups) was used. The Spearman correlation coefficient was calculated for evaluation of the correlation between factors with qualitative or ordinal quantities and questions or domains of QoL questionnaires. Logistic regression (forward stepwise method) was used to identify factors affecting the individual domains of QoL questionnaires (separate multivariable logistic model for each domain or question; totally 12 models). The following variables were used for logistic regression analysis: age (quantitative data); gender (qualitative data); marital status (semi-quantitative data); social situation (semi-quantitative data); level of education (semi-quantitative data); presence of arterial hypertension, diabetes mellitus, hyperlipidemia, coronary heart disease, or atrial fibrillation; history of myocardial infarction, other heart disease, stroke, transient ischemic attack, carotid endarterectomy, carotid artery stenting, coronary artery bypass graft, surgery for peripheral arterial disease, coronary artery stenting (all qualitative data; combination of selfreports and medical reports); smoking (self-report); alcohol consumption (self-report; 1 international unit $=10 \mathrm{~mL}$ of pure alcohol); BMI; systolic blood pressure; diastolic blood pressure; visual pain scale (all quantitative data). The quantitative values of the 4 domains in WHOQoLBREF were dichotomized with a cut-off value of 13, Q1 and Q2 in WHOQoL-BREF with a cut-off value of $3(1+$ 2 vs. $3+4+5), 5$ domains in EQ-5D-3 L with a cut-off value of 2 ( 1 vs. $2+3)$, and the visual analogue scale in EQ-5D-3 L with a cut-off value of 51.

All tests were carried out at an alpha level of significance of 0.05. All data were analyzed using IBM SPSS Statistics (v22.0; SPSS, Inc., Chicago, IL, USA).

\section{Results}

Of the 584 consecutive patients examined in the Neurosonology Laboratory, 502 met the inclusion criteria, and 344 completed both QoL questionnaires (164 men; 
mean age, $69.7 \pm 7.8$ years) over a 3-month interval (April-June 2016) - Fig. 1. Demographic data are presented in Table 1 . There was no statistically significant difference in any demographic parameter between completers (patients who completed the questionnaires) and non-completers ( $p<0.05$ for all items). Cronbach's alpha for particular subscales in WHOQoL-BREF in the presented study varied between 0.73 and 0.82 . Cronbach's alpha for EQ-5D-3 L was 0.74 .

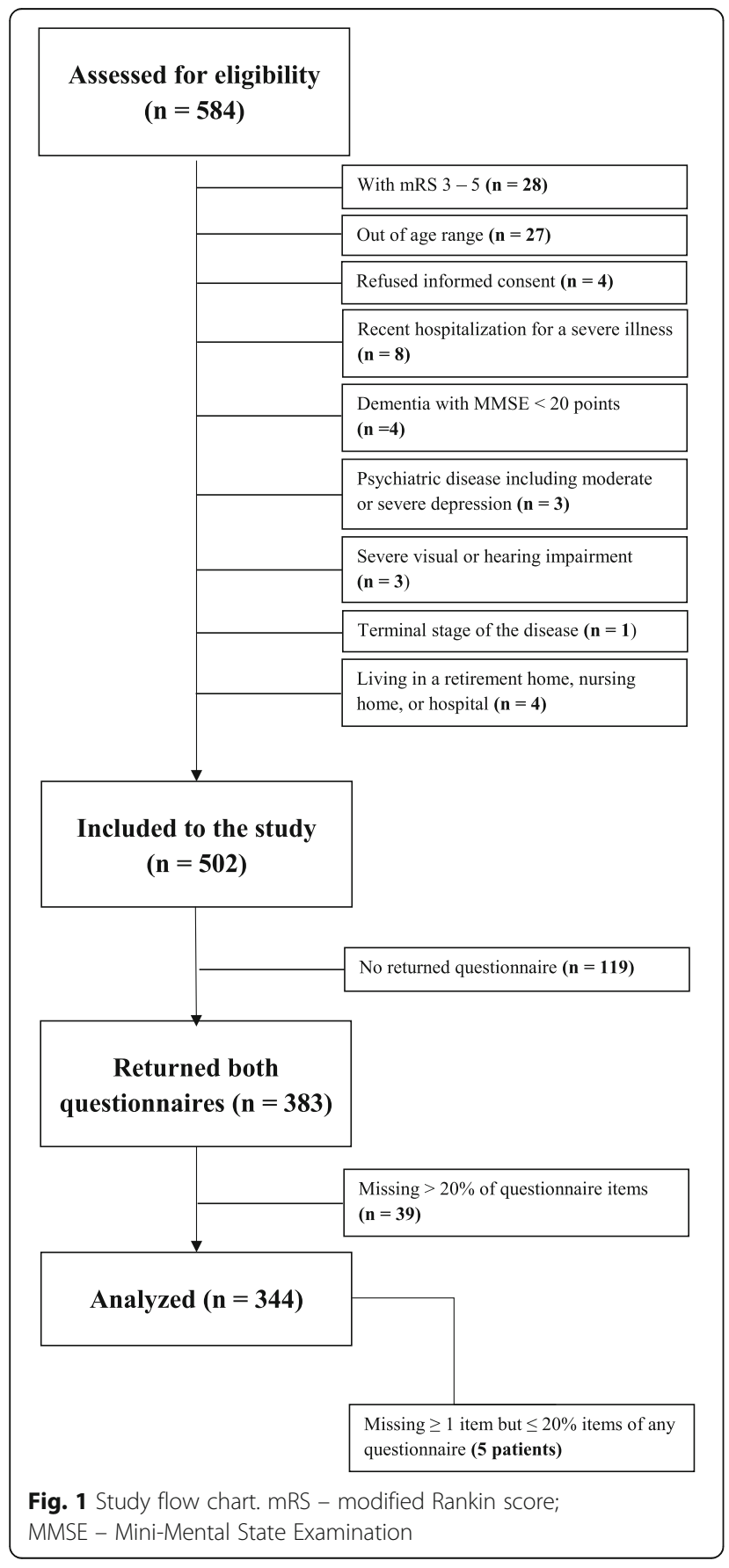

The correlations between observed factors and QoL in particular domains are shown in Table 2. Factors negatively influencing the QoL were identified using the forward stepwise method of multiple logistic regression and are presented in Tables 3 and 4.

In the WHOQoL-BREF questionnaire, pain was identified as an independent predictor of worse QoL in all domains and questions (OR per 1 unit in the visual pain scale $=0.593-0.852, p<0.01$ for all cases) - Table 3. Furthermore, the factors influencing the overall perception of QoL (Q1) were living with a partner $(\mathrm{OR}=2.509, p=0.004)$, level of education $(\mathrm{OR}=2.572$ for secondary with graduation, $p=0.014$, $\mathrm{OR}=4.351$ for tertiary, $p=0.008)$, and diastolic blood pressure $(\mathrm{OR}=0.672, p=0.023)$. Male gender was identified as an independent factor positively influencing the overall perception of health (Q2; OR $=1.784, p=0.015)$ and, the psychological domain (DOM2; OR $=0.910$, $p=0.044)$, and negatively influencing the social relationships domain (DOM 3; OR $=0.543, p=0.048$ ). Diastolic blood pressure independently influenced the QoL in the overall perception of health $(\mathrm{Q} 2 ; \mathrm{OR}=0.477$, $p<0.001$ ) and the physical health domain (DOM1; $\mathrm{OR}=0.961, p=0.027$ ).

In the EQ-5D-3 L questionnaire, the independent predictor of worse QoL in all domains and current health status was pain (OR per 1 level in the 10-level visual analogue pain scale $=0.505-0.787, p<0.01$ for all cases) Table 4. Moreover, age $(\mathrm{OR}=0.962, p=0.028)$, gender $(\mathrm{OR}=0.492$ for male gender, $p=0.011)$, living with a partner $(\mathrm{OR}=2.037, p=0.035)$, education level $(\mathrm{OR}=1.448$ for secondary with graduation, $p=0.007)$, and $\mathrm{BMI}(\mathrm{OR}=$ 0.895, $p=0.001$ ) were identified as factors independently influencing the mobility domain (DOM1). Male gender ( $\mathrm{OR}=1.741, p=0.021$ ) positively influenced the anxiety/ depression domain (DOM 5). The education level (OR = 1.332 for secondary with graduation, $p=0.023$ ) and systolic blood pressure ( $\mathrm{OR}=0.787, p=0.014)$ were identified as independent factors influencing the current health status measured on the visual analogue scale.

A history of stroke, transient ischemic attack, myocardial infarction, arterial hypertension, diabetes mellitus, hyperlipidemia, coronary heart disease, atrial fibrillation, arterial surgery, stenting, smoking, and alcohol consumption had no significant influence on QoL in both questionnaires ( $p>0.05$ for all cases).

\section{Discussion}

The present study demonstrated that a history of vascular events (stroke, transient ischemic attack, coronary heart disease, and myocardial infarction), risk factors influencing progression of atherosclerosis (arterial hypertension, diabetes mellitus, hyperlipidemia, smoking, and alcohol consumption), and vascular interventions for 
Table 1 Demographic data of patients selected for the study, completers (patients who completed the questionnaires) and noncompleters (patients excluded from the study)

\begin{tabular}{|c|c|c|c|c|c|}
\hline & & $\begin{array}{l}\text { Patients selected for the study } \\
(n=502)\end{array}$ & $\begin{array}{l}\text { Completers ( } 344 \\
\text { patients) }\end{array}$ & $\begin{array}{l}\text { Non-completers }(n \\
=158)\end{array}$ & $\begin{array}{l}P \\
\text { value* }\end{array}$ \\
\hline \multicolumn{2}{|l|}{ Male gender; n (\%) } & $260(51.8)$ & $164(47.7)$ & $96(60.8)$ & $0.006^{\mathrm{a}}$ \\
\hline \multicolumn{2}{|l|}{ Age, years; median, mean $\pm S D$} & $71,70.0 \pm 7.6$ & $71,69.5 \pm 7.8$ & $72,70.8 \pm 7.0$ & $0.069^{b}$ \\
\hline \multicolumn{2}{|l|}{ Weight, kg; median, mean \pm SD } & $81,81.1 \pm 15.3$ & $80,80.4 \pm 14.9$ & $82,82.6 \pm 15.9$ & $0.144^{b}$ \\
\hline \multicolumn{2}{|l|}{ Height, $\mathrm{cm}$; median, mean \pm SD } & $168,168.9 \pm 8.4$ & $169,169.0 \pm 8.3$ & $169,169.2 \pm 8.6$ & $0.523^{b}$ \\
\hline \multicolumn{2}{|c|}{ Body mass index; median, mean \pm SD } & $28,28.3 \pm 4.4$ & $28,28.1 \pm 4.2$ & $29,28.7 \pm 4.7$ & $0.357^{b}$ \\
\hline \multicolumn{2}{|c|}{ Systolic blood pressure, $\mathrm{mm} \mathrm{Hg}$; median, mean \pm SD } & $135,135.1 \pm 12.4$ & $135,134.8 \pm 12.3$ & $136,135.6 \pm 12.6$ & $0.412^{b}$ \\
\hline \multicolumn{2}{|c|}{ Diastolic blood pressure, $\mathrm{mm} \mathrm{Hg}$; median, mean $\pm \mathrm{SD}$} & $80,79.4 \pm 8.3$ & $80,79.3 \pm 8.4$ & $80,79.6 \pm 8.2$ & $0.498^{b}$ \\
\hline \multicolumn{2}{|c|}{ Visual pain scale; median, mean \pm SD } & $4,3.8 \pm 2.5$ & $4,3.9 \pm 2.5$ & $4,3.6 \pm 2.5$ & $0.168^{\mathrm{b}}$ \\
\hline \multicolumn{2}{|l|}{ Arterial hypertension; n (\%) } & $429(85.5)$ & $141(89.2)$ & $141(89.2)$ & $0.083^{\mathrm{a}}$ \\
\hline \multicolumn{2}{|l|}{ Diabetes mellitus; n (\%) } & $115(22.9)$ & $39(24.7)$ & $39(24.7)$ & $0.528^{\mathrm{a}}$ \\
\hline \multicolumn{2}{|l|}{ Hyperlipidemia; n (\%) } & $268(53.4)$ & $191(55.5)$ & $77(48.7)$ & $0.294^{\mathrm{a}}$ \\
\hline \multicolumn{2}{|l|}{ Coronary heart disease; $n$ (\%) } & $156(31.1)$ & 99 (28.8) & $57(36.1)$ & $0.109^{\mathrm{a}}$ \\
\hline \multicolumn{2}{|l|}{ Myocardial infarction; n (\%) } & $49(9.8)$ & $35(10.2)$ & $14(8.9)$ & $0.639^{\mathrm{a}}$ \\
\hline \multicolumn{2}{|l|}{ Atrial fibrillation; n (\%) } & $66(13.1)$ & $43(12.5)$ & $23(14.6)$ & $0.711^{\mathrm{a}}$ \\
\hline \multicolumn{2}{|l|}{ Other heart disease; n (\%) } & $53(10.6)$ & $32(9.3)$ & $21(13.3)$ & $0.203^{\mathrm{a}}$ \\
\hline \multicolumn{2}{|l|}{ Transient ischemic attack; n (\%) } & $57(11.4)$ & $42(12.2)$ & $15(9.5)$ & $0.624^{\mathrm{a}}$ \\
\hline \multicolumn{2}{|l|}{ Stroke; n (\%) } & $217(43.2)$ & $145(42.2)$ & $72(45.6)$ & $0.535^{\mathrm{a}}$ \\
\hline \multicolumn{2}{|l|}{ Surgery/stenting of arteries; n (\%) } & $106(21.1)$ & 79 (23.0) & $27(17.1)$ & $0.120^{\mathrm{a}}$ \\
\hline \multicolumn{2}{|l|}{ Smoking; n (\%) } & $62(12.4)$ & $49(14.2)$ & $13(8.2)$ & $0.057^{\mathrm{a}}$ \\
\hline \multirow[t]{3}{*}{ Social situation; n (\%) } & Living alone & $111(22.1)$ & $72(21.0)$ & $39(24.7)$ & \multirow[t]{3}{*}{$0.268^{\circ}$} \\
\hline & Living with partner & $94(18.7)$ & $60(17.4)$ & $34(21.5)$ & \\
\hline & Living with family & $297(59.2)$ & $212(61.6)$ & $85(53.8)$ & \\
\hline \multirow[t]{4}{*}{ Education; n (\%) } & Primary & $106(21.1)$ & $67(19.5)$ & 39 (24.7) & \multirow[t]{4}{*}{$0.152^{\mathrm{C}}$} \\
\hline & $\begin{array}{l}\text { Secondary without } \\
\text { graduation }\end{array}$ & $146(29.1)$ & $104(30.2)$ & 42 (26.6) & \\
\hline & $\begin{array}{l}\text { Secondary with } \\
\text { graduation }\end{array}$ & $160(31.9)$ & 115 (33.4) & 45 (28.5) & \\
\hline & Tertiary & 90 (17.9) & $58(16.9)$ & $32(20.3)$ & \\
\hline \multirow{4}{*}{$\begin{array}{l}\text { Alcohol consumption, units/day; } \\
\text { n (\%) }\end{array}$} & 0 & $253(50.4)$ & $170(49.4)$ & $83(52.5)$ & \multirow[t]{4}{*}{$0.244^{c}$} \\
\hline & 1 & $143(28.5)$ & $109(31.7)$ & $34(21.5)$ & \\
\hline & 2 & 100 (19.9) & $60(17.4)$ & $40(25.3)$ & \\
\hline & $\geq 3$ & $6(1.2)$ & $5(1.5)$ & $1(0.6)$ & \\
\hline
\end{tabular}

$\mathrm{n}$ - number; SD - standard deviation; * global test comparing the distributions of completers and non-completers; ${ }^{\text {a }}$ Fisher's exact test; ${ }^{\mathrm{b}}$ Student's $t$-test;

c- Kruskal-Wallis test

atherosclerotic stenoses were not associated with QoL in self-sufficient patients with carotid atherosclerotic stenosis and without dementia or moderate or severe depression. The only factors influencing the QoL in these patients were pain, blood pressure, and BMI, living situation, level of education, age and gender. Thus, the current patient's situation and health status, but not the medical history were the main factors influencing the evaluation of QoL in these patients.

The interesting result of our study was that the presence of arterial hypertension was not identified as a factor influencing the QoL in both questionnaires, in contrast to actual blood pressure, which was negatively correlated with satisfaction with health status, satisfaction with the QoL, and physical health domain evaluation measured on the WHOQoL-BREF, and the current health status measured on the EQ-5D-3 L. Lower blood pressure was associated with a better QoL and a better sense of patient well-being, as in previous studies [31, 32]. Obesity represents another factor with potential influence on the QoL [33, 34]. BMI was identified as a factor negatively correlated 
Table 2 Correlation between questions or domains of quality of life questionnaires and evaluated risk factors

\begin{tabular}{|c|c|c|c|c|c|c|c|c|c|c|c|c|}
\hline & \multicolumn{6}{|c|}{ WHO-QOL BREF } & \multicolumn{6}{|c|}{ EQ-5D-3 L } \\
\hline & Q1 & Q2 & DOM1 & DOM2 & DOM3 & DOM4 & DOM1 & $\mathrm{DOM} 2$ & DOM3 & DOM4 & DOM5 & Health status \\
\hline $\mathrm{Age}^{\mathrm{a}}$ & -0.011 & -0.013 & $-0.124^{*}$ & -0.088 & -0.066 & 0.099 & $0.127^{*}$ & 0.101 & $0.118^{*}$ & 0.086 & 0.022 & -0.081 \\
\hline Gender $^{\mathrm{b}}$ & 0.249 & 0.074 & 0.938 & 0.607 & 0.020 & 0.974 & 0.050 & 0.064 & 0.043 & 0.301 & 0.015 & 0.055 \\
\hline Spouse $^{b}$ & 0.020 & 0.070 & 0.090 & 0.777 & 0.350 & 0.340 & 0.031 & 0.417 & 0.836 & 0.026 & 0.304 & 0.651 \\
\hline Living alone $^{c}$ & 0.002 & 0.108 & 0.014 & 0.507 & 0.154 & 0.045 & 0.066 & 0.799 & 0.262 & 0.014 & 0.040 & 0.344 \\
\hline Education $^{a}$ & $0.266^{*}$ & 0.104 & $0.255^{*}$ & $0.195^{*}$ & $0.129^{*}$ & $0.227^{*}$ & $-0.190^{*}$ & -0.096 & $-0.143^{*}$ & $-0.180^{*}$ & -0.080 & $0.172^{*}$ \\
\hline Arterial hypertension ${ }^{\text {b }}$ & 0.639 & 0.889 & 0.376 & 0.768 & 0.321 & 0.536 & 0.060 & 0.336 & 0.061 & 0.465 & 0.457 & 0.429 \\
\hline Diabetes mellitus ${ }^{\mathrm{b}}$ & 0.642 & 0.052 & 0.106 & 0.912 & 0.108 & 0.351 & 0.102 & 0.052 & 0.253 & 0.098 & 0.228 & 0.006 \\
\hline Hyperlipidemia $^{\text {b }}$ & 0.691 & 0.463 & 0.053 & 0.222 & 0.851 & 0.434 & 0.057 & 0.616 & 0.108 & 0.472 & 0.927 & 0.464 \\
\hline Coronary heart disease $^{b}$ & 0.411 & 0.529 & 0.087 & 0.925 & 0.507 & 0.204 & 0.108 & 0.514 & 0.618 & 0.054 & 0.727 & 0.228 \\
\hline Atrial fibrillation ${ }^{b}$ & 0.186 & 0.423 & 0.837 & 0.146 & 0.986 & 0.137 & 0.915 & 0.733 & 0.935 & 0.778 & 0.323 & 0.852 \\
\hline Myocardial infarction ${ }^{b}$ & 0.529 & 0.778 & 0.551 & 0.574 & 0.591 & 0.116 & 0.622 & 0.303 & 0.142 & 0.492 & 0.105 & 0.544 \\
\hline Other heart disease ${ }^{b}$ & 0.315 & 0.611 & 0.877 & 0.192 & 0.154 & 0.059 & 0.954 & 0.701 & 0.890 & 0.571 & 0.521 & 0.727 \\
\hline Stroke/TIA ${ }^{b}$ & 0.102 & 0.726 & 0.166 & 0.444 & 0.212 & 0.664 & 0.452 & 0.810 & 0.379 & 0.529 & 0.120 & 0.315 \\
\hline Carotid endarterectomyb & 0.055 & 0.782 & 0.946 & 0.343 & 0.095 & 0.403 & 0.253 & 0.269 & 0.704 & 0.415 & 0.318 & 0.661 \\
\hline$C A B G^{b}$ & 0.649 & 0.218 & 0.729 & 0.248 & 0.832 & 0.752 & 0.073 & 0.516 & 0.804 & 0.454 & 0.248 & 0.106 \\
\hline Surgery for $P A D^{b}$ & 0.051 & 0.441 & 0.173 & 0.229 & 0.778 & 0.301 & 0.337 & 0.435 & 0.505 & 0.309 & 0.051 & 0.204 \\
\hline Carotid artery stenting ${ }^{\mathrm{b}}$ & 0.793 & 0.660 & 0.425 & 0.860 & 0.780 & 0.766 & 0.580 & 0.109 & 0.119 & 0.381 & 0.444 & 0.748 \\
\hline Coronary artery stenting ${ }^{b}$ & 0.623 & 0.869 & 0.611 & 0.980 & 0.750 & 0.224 & 0.183 & 0.825 & 0.430 & 0.903 & 0.960 & 0.256 \\
\hline Smoking ${ }^{b}$ & 0.581 & 0.799 & 0.824 & 0.595 & 0.539 & 0.265 & 0.074 & 0.401 & 0.699 & 0.827 & 0.197 & 0.463 \\
\hline Alcohol abuse $^{b}$ & 0.555 & 0.164 & 0.099 & 0.581 & 0.829 & 0.256 & 0.268 & 0.133 & 0.213 & 0.115 & 0.615 & 0.700 \\
\hline Body mass index ${ }^{a}$ & 0.023 & -0.036 & -0.060 & 0.039 & 0.065 & 0.014 & $0.137^{*}$ & -0.061 & 0.025 & 0.050 & 0.038 & -0.027 \\
\hline Systolic blood pressure ${ }^{a}$ & $-0.117^{*}$ & $-0.148^{*}$ & $-0.138^{*}$ & $-0.154^{*}$ & $-0.112^{*}$ & $-0.109^{*}$ & $0.108^{*}$ & $0.110^{*}$ & $0.108^{*}$ & 0.085 & 0.096 & $-0.174^{*}$ \\
\hline Diastolic blood pressure ${ }^{a}$ & $-0.125^{*}$ & $-0.192^{*}$ & $-0.150^{*}$ & $-0.159^{*}$ & $-0.129^{*}$ & $-0.112^{*}$ & $0.112^{*}$ & $0.130^{*}$ & 0.102 & 0.065 & 0.065 & $-0.172^{*}$ \\
\hline Visual pain scale $e^{a}$ & $-0.306^{*}$ & $-0.297^{*}$ & $-0.637^{*}$ & $-0.432^{*}$ & $-0.328^{*}$ & $-0.377^{*}$ & $0.445^{*}$ & $0.214^{*}$ & $0.338^{*}$ & $0.556^{*}$ & $0.360^{*}$ & $-0.441^{*}$ \\
\hline
\end{tabular}

Used method, value: ${ }^{\text {a }}$ - Spearmann correlation, Spearman correlation coefficient $(\mathrm{r}){ }^{\mathrm{b}}$ - Mann-Whitney U-test, $P$ value; ${ }^{\mathrm{c}}-\mathrm{Kruskal-Wallis}$ test, $P$ value; WHO-QOL BREF - World Health Organization Quality of Life short version; EQ-5D-3 L - the 3-item EuroQol-5D; TIA - transient ischemic attack; CABG - coronary artery bypass graft; PAD - peripheral artery disease; WHO-QOL: Q1 - overall perception of quality of life; Q2 - the overall perception of their health; DOM1 - physical health domain; DOM2 - psychological domain; DOM3 - social relationships domain; DOM4- environment domain; EQ-5D-3 L: DOM1 - mobility domain;

DOM2 - self-care domain; DOM3 - usual activities domain; DOM4 - pain/discomfort domain; DOM5- anxiety/depression domain; ${ }^{*}-P<0.05$

with QoL in the mobility domain measured on the EQ-5D-3 L in our study. Ford et al. [35] showed, also, that increased BMI significantly impaired healthrelated QoL and affected a physical functioning more strongly than mental functioning.

Social situation was a factor influencing the overall perception of QoL measured on the WHOQoL-BREF and mobility measured on the EQ-5D-3 L. Patients living alone scored significantly worse in both domains. Loneliness is a known factor negatively influencing QoL in chronically ill patients or stroke survivors [36-38].

In agreement with other studies, pain was identified as a strong independent predictor of lower QoL in all domains of both questionnaires in our study [39-41].

Gender was identified as a factor significantly influencing QoL in the psychological domain and satisfaction with present health status (worse in females), and social relationships domains (worse in males) measured on the WHOQoL-BREF, and mobility measured on the EQ-5D$3 \mathrm{~L}$. The results of published studies evaluating the influence of gender on QoL are inconclusive. Jönsson et al. [42] reported that female gender is associated with higher scores for the physical role, emotional function, and the general health in stroke survivors. In contrast, van Eeden et al. [43] demonstrated higher QoL in males compared to females 2, 6, and 12 months after stroke; however, it should be pointed out that not only poststroke patients were enrolled in our study.

Age was the second non-modifiable factor influencing the QoL. Nevertheless, age only correlated significantly with QoL in the mobility domain measured on the EQ-5D-3 L. A recently published Dutch study confirmed that age influenced the elderly predominantly in the mobility domain of all domains in the EQ-5D-3 L questionnaire [44]. 
Table 3 Factors affecting the individual domains of quality of life in WHOQOL-BREF questionnaire - logistic regression, forward stepwise method, separate model for each question or domain

\begin{tabular}{|c|c|c|c|c|}
\hline Question/ Domain & Factor $^{\mathrm{a}}$ & OR & $95 \mathrm{Cl}$ & $P$ value \\
\hline \multirow[t]{11}{*}{ Q1 } & Social situation & & & \\
\hline & - living alone & reference & & \\
\hline & - living with a family member & 1.649 & $0.734-3.705$ & 0.226 \\
\hline & - living with a partner & 2.509 & $1.349-4.972$ & 0.004 \\
\hline & Education level & & & \\
\hline & - primary & reference & & \\
\hline & - secondary without graduation & 1.177 & $0.578-2.397$ & 0.653 \\
\hline & - secondary with graduation & 2.572 & $1.206-5.484$ & 0.014 \\
\hline & - tertiary & 4.351 & $1.461-12.957$ & 0.008 \\
\hline & Diastolic blood pressure (per $10 \mathrm{mmHg}$ ) & 0.672 & $0.477-0.956$ & 0.023 \\
\hline & Pain (per 1 point in the Visual pain scale) & 0.852 & $0.759-0.956$ & 0.007 \\
\hline \multirow[t]{5}{*}{ Q2 } & Gender & & & \\
\hline & - female & reference & & \\
\hline & - male & 1.784 & $1.117-2.850$ & 0.015 \\
\hline & Diastolic blood pressure (per $10 \mathrm{mmHg}$ ) & 0.477 & $0.341-0.667$ & $<0.001$ \\
\hline & Pain (per 1 point in the Visual pain scale) & 0.798 & $0.724-0.879$ & $<0.001$ \\
\hline \multirow[t]{7}{*}{ DOM 1} & Education level & & & \\
\hline & - primary & reference & & \\
\hline & - secondary without graduation & 2.472 & $1.125-5.432$ & 0.024 \\
\hline & - secondary with graduation & 2.956 & $1.364-6.406$ & 0.006 \\
\hline & - tertiary & 1.871 & $0.749-4.675$ & 0.180 \\
\hline & Diastolic blood pressure (per 10 mmHg) & 0.961 & $0.928-0.995$ & 0.027 \\
\hline & Pain (per 1 point in the Visual pain scale) & 0.593 & $0.519-0.678$ & $<0.001$ \\
\hline \multirow[t]{4}{*}{ DOM 2} & Gender & & & \\
\hline & - female & reference & & \\
\hline & - male & 1.910 & $1.016-3.591$ & 0.044 \\
\hline & Pain (per 1 point in the Visual pain scale) & 0.673 & $0.585-0.773$ & $<0.001$ \\
\hline \multirow[t]{4}{*}{ DOM 3} & Gender & & & \\
\hline & - female & reference & & \\
\hline & - male & 0.543 & $0.297-0.994$ & 0.048 \\
\hline & Pain (per 1 point in the Visual pain scale) & 0.785 & $0.692-0.890$ & $<0.001$ \\
\hline DOM 4 & Pain (per 1 point in the Visual pain scale) & 0.619 & $0.511-0.750$ & $<0.001$ \\
\hline
\end{tabular}

a- only factors significantly influencing the corresponding question or domain with $p<0.05$ are mentioned; WHO-QOL BREF - World Health Organization Quality of Life short version; EQ-5D-3 L - the 3-item EuroQol-5D; WHO-QOL: Q1 - overall perception of quality of life; Q2 - the overall perception of their health; DOM1 - physical health domain; DOM2 - psychological domain; DOM3 - social relationships domain; DOM4 - environment domain

The last identified factor influencing the QoL was level of education. Level of education was negatively correlated with the overall perception of QoL measured on the WHOQoL-BREF, satisfaction of present health status, and QoL in the mobility domain measured on the EQ-5D-3 L. The World Health Organization has determined education to be one of the social determinants of health because low education levels are linked with poor health, more stress and lower self-confidence [45]. Education has also been identified as an independent factor positively influencing QoL in the study performed by Vlajinac et al. [22].

The severity and character of persisting neurologic deficits after stroke could be additional factors influencing the QoL in patients with carotid stenosis [46-49]. A Korean study showed that patients with stroke and facial palsy evaluated their QoL worse than patients with dysarthria [47]. Also, persistent visual deficits, hemiparesis, and recurrent stroke could influence the QoL significantly $[48,49]$. We did not identify persistent 
Table 4 Factors affecting the individual domains of quality of life in EQ-5D-3 L questionnaire - logistic regression, forward stepwise method

\begin{tabular}{|c|c|c|c|c|}
\hline Question/ Domain & Factor $^{a}$ & OR & $95 \mathrm{Cl}$ & $P$ value \\
\hline \multirow[t]{15}{*}{$\overline{\mathrm{DOM} 1}$} & Age (per 1 year) & 0.962 & $0.929-0.996$ & 0.028 \\
\hline & \multicolumn{4}{|l|}{ Gender } \\
\hline & - female & reference & & \\
\hline & - male & 0.492 & $0.285-0.851$ & 0.011 \\
\hline & \multicolumn{4}{|l|}{ Social situation } \\
\hline & - living alone & reference & & \\
\hline & - living with a family member & 1.322 & $0.775-2.758$ & 0.152 \\
\hline & - living with a partner & 2.037 & $1.052-3.953$ & 0.035 \\
\hline & \multicolumn{4}{|l|}{ Education level } \\
\hline & - primary & reference & & \\
\hline & - secondary without graduation & 1.201 & $0.610-2.219$ & 0.385 \\
\hline & - secondary with graduation & 1.448 & $1.108-1.893$ & 0.007 \\
\hline & - tertiary & 1.319 & $0.698-2.441$ & 0.208 \\
\hline & Body mass index (per 1 unit) & 0.895 & $0.839-0.955$ & 0.001 \\
\hline & Pain (per 1 point in the Visual pain scale) & 0.638 & $0.567-0.718$ & $<0.001$ \\
\hline DOM2 & Pain (per 1 point in the Visual pain scale) & 0.750 & $0.646-0.871$ & $<0.001$ \\
\hline DOM3 & Pain (per 1 point in the Visual pain scale) & 0.718 & $0.644-0.801$ & $<0.001$ \\
\hline DOM4 & Pain (per 1 point in the Visual pain scale) & 0.505 & $0.429-0.594$ & $<0.001$ \\
\hline \multirow[t]{4}{*}{ DOM5 } & \multicolumn{4}{|l|}{ Gender } \\
\hline & - female & reference & & \\
\hline & - male & 1.741 & $1.089-2.783$ & 0.021 \\
\hline & Pain (per 1 point in the Visual pain scale) & 0.721 & $0.651-0.798$ & $<0.001$ \\
\hline \multirow[t]{7}{*}{ Health status } & \multicolumn{4}{|l|}{ Education level } \\
\hline & - primary & reference & & \\
\hline & - secondary without graduation & 1.098 & $0.504-1.944$ & 0.612 \\
\hline & - secondary with graduation & 1.332 & $1.041-1.705$ & 0.023 \\
\hline & - tertiary & 1.297 & $0.649-2.168$ & 0.428 \\
\hline & Systolic blood pressure (per 10 mmHg) & 0.787 & $0.650-0.953$ & 0.014 \\
\hline & Pain (per 1 point in the Visual pain scale) & 0.782 & $0.708-0.864$ & $<0.001$ \\
\hline
\end{tabular}

a. only factors significantly influencing the corresponding question or domain with $p<0.05$ are mentioned; EQ-5D-3 L: DOM1 - mobility domain; DOM2 - self-care domain; DOM3 - usual activities domain; DOM4 - pain/discomfort domain; DOM5 - anxiety/depression domain

neurologic deficits as a factor influencing QoL in patients after stroke if self-sufficient. Nevertheless, the character and severity of neurologic deficits were not evaluated in the present study.

Comparing the ability of both questionnaires to identify factors influencing QoL, the EQ-5D-3 L questionnaire identified not only the same five independent factors (gender, level of education, living alone, pain, and blood pressure) as the WHOQoL-BREF questionnaire, but two additional factors (age and body mass index). Furthermore, the EQ-5D-3 L questionnaire consisted of only 5 questions and 1 visual analogue scale in comparison with 26 questions in the WHOQoL-BREF. These results showed that the EQ-5D-3 L questionnaire is more suitable than the WHOQoL-BREF for patients with carotid stenosis.

The main limitation of the study was patient selection. We enrolled only self-sufficient patients visiting the Neurosonology Laboratory for the evaluation of atherosclerosis of the carotid arteries. Thus, patients with other etiologies of stroke could be neglected. The second limitation was the monocentric character of the study. Third, patients recently hospitalized for a severe illness, patients with dementia, psychiatric disease, including moderate or severe depression, severe visual or hearing impairment, patients in a terminal stage of the disease, and patients living in a retirement home, nursing home, or hospital were excluded to avoid uncontrolled bias. 
Only $4 \%$ of screened patients were excluded due to these reasons. Thus, the results should be generalizable. Nevertheless, in further studies, the extension of inclusion criteria, recorded variables and sample size may enable enrollment of a more heterogenous group of patients with carotid stenosis and may subsequently identify more predictors of QoL.

\section{Conclusion}

Pain, blood pressure, BMI, education, living alone, gender, and age, but not a previous stroke or myocardial infarction, affect the QoL in self-sufficient patients with carotid stenosis without dementia or severe depression. Thus, current social and health status factors should be recorded in studies with carotid stenosis patients. Awareness and understanding of the factors influencing QoL in patients with carotid stenosis should be important to support a maintained or increased QoL and may also lead to more holistic management and patient care.

\section{Abbreviations}

BMI: Body mass index; EQ-5D-3 L: 3-Level EuroQol-5D; QoL: Quality of life; WHOQOL-BREF: World Health Organization Quality of Life [short version]

\section{Acknowledgments}

This study was supported by the grant of Palacký University Olomouc No. IGA_FZV_2016_004 and partially supported by Ministry of Health of the Czech Republic, grants No. 16-29148A and 16-30965A.

\section{Ethics approval and consent for participate}

Local Ethics Committee of Faculty of Health Sciences, Palacký University Olomouc approved the study protocol (No. UPOL-7279/1040-2016) and participation consent was obtained from all subjects.

\section{Funding}

This study was supported by the grant of Palacký University Olomouc No. IGA_FZV_2016_004 and partially supported by Ministry of Health of the Czech Republic, grants No. 16-29148A and 16-30965A.

\section{Availability of data and materials}

The datasets generated during and/or analyzed during the current study are not publicly available due to patient information, but are available from the corresponding author on reasonable request.

\section{Authors' contributions}

TF and DŠ made substantial contributions to designing the study, analyzing the data, and interpreting the results. TF wrote the first draft of the manuscript. KL contributed to data analysis and drafting of the manuscript. $\mathrm{RH}$ and $\mathrm{ZM}$ made substantial contributions to designing the study, interpreting the results, and critically revising the manuscript. All authors read and approved the final version of the manuscript.

\section{Competing interests}

The authors declare that they have no competing interests.

\section{Publisher's Note}

Springer Nature remains neutral with regard to jurisdictional claims in published maps and institutional affiliations.

\section{Author details}

${ }^{1}$ Department of Nursing, Faculty of Health Sciences, Palacký University Olomouc, Olomouc, Czech Republic. ${ }^{2}$ Center for Science and Research, Department of Nursing, Faculty of Health Sciences, Palacký University Olomouc, Hněvotínská 3, CZ-775 15 Olomouc, Czech Republic. ${ }^{3}$ Department of Neurology, Comprehensive Stroke Center, Charles University Faculty of
Medicine and University Hospital Hradec Králové, Hradec Králové, Czech Republic. ${ }^{4}$ Department of Biophysics, Faculty of Medicine and Dentistry, Institute of Molecular and Translational Medicine, Palacký University, Olomouc, Czech Republic.

Received: 23 February 2017 Accepted: 16 April 2018

Published online: 27 April 2018

\section{References}

1. Celermajer DS, Chow CK, Marijon E, Anstey NM, Woo KS. Cardiovascular disease in the developing world. Prevalences, patterns, and the potential of early disease detection. J Am Coll Cardiol. 2012;60(14):1207-16.

2. Romero JR, Vasan RS, Beiser AS, et al. Association of Carotid Artery Atherosclerosis with circulating biomarkers of extracellular matrix remodeling: the Framingham offspring study. J Stroke Cerebrovasc Dis. 2008;17(6):412-7.

3. Wolf ME, Sauer T, Alonso A, Hennerici MG. Comparison of the new ASCO classification with the TOAST classification in a population with acute ischemic stroke. J Neurol. 2012;259(7):1284-9.

4. Rundek T, Sacco RL. Prognosis after stroke. In: Grotta JC, Albers GW, Broderick JP, et al., editors. Stroke: pathophysiology, diagnosis, and management. 6th ed. Philadelphia: Elsevier Health Sciences; 2016. p. 234.

5. Feigin VL, Roth GA, Naghavi M, et al. Global burden of diseases, injuries and risk factors study 2013 and stroke experts writing group. Global burden of stroke and risk factors in 188 countries, during 1990-2013: a systematic analysis for the global burden of disease study 2013. Lancet Neurol. 2016; 15(9):913-24.

6. Ojaghihaghighi S, Vahdati SS, Mikaeilpour A, Ramouz A. Comparison of neurological clinical manifestation in patients with hemorrhagic and ischemic stroke. World J Emerg Med. 2017;8(1):34-8.

7. Marx J, Hockberger R, Walls R. Rosen's Emergency Medicine (6th edition); 2006. p. 1606-19.

8. Tintinalli JE, Kelen GD, Stapczynski JS. Emergency Medicine: A Comprehensive Study Guide. 6th ed; 2004. p. 1382-9.

9. Rabinstein AA. Treatment of acute ischemic stroke. Continuum (Minneap Minn). 2017;23:62-81.

10. Chen CJ, Ding D, Starke RM, et al. Endovascular vs medical management of acute ischemic stroke. Neurology. 2015;85(22):1980-90.

11. Balami JS, Sutherland BA, Edmunds LD, et al. A systematic review and metaanalysis of randomized controlled trials of endovascular thrombectomy compared with best medical treatment for acute ischemic stroke. Int J Stroke. 2015;10(8):1168-78.

12. Volný $\mathrm{O}$, Krajina $\mathrm{A}, \mathrm{Bar} \mathrm{M}$, et al. Results of interventional studies $\mathrm{Mr}$ Clean, Escape, Swift Prime, Extend-la, Revascat. Cesk Slov Neurol N. 2016;79/112(1):100-10.

13. Pollock A, Baer G, Campbell $P$, et al. Physical rehabilitation approaches for the recovery of function and mobility following stroke. Cochrane Database Syst Rev. 2014:4:CD001920.

14. Carota A, Dieguez S, Bogousslavsky J. Psychopathology of stroke. Psychol Neuropsychiatr Vieil. 2005:3(4):235-49.

15. Fisher AR. Development of clinical practice guidelines for urinary continence care of adult stroke survivors in acute and rehabilitation settings. Can J Neurosci Nurs. 2014;36(3):16-31.

16. Fransen PS, Beumer D, Berkhemer OA, et al. MR CLEAN investigators. MR CLEAN, a multicenter randomized clinical trial of endovascular treatment for acute ischemic stroke in the Netherlands: study protocol for a randomized controlled trial. Trials. 2014:15:343.

17. ENOS Trial Investigators, Bath PM, Woodhouse L, et al. Efficacy of nitric oxide, with or without continuing antihypertensive treatment, for management of high blood pressure in acute stroke (ENOS): a partialfactorial randomised controlled trial. Lancet. 2015;385(9968):617-28.

18. $\quad H F$, Indredavik $B$, Johnsen $R$, Lydersen $S$. Acute stroke unit care combined with early supported discharge. Long-term effects on quality of life. A randomized controlled trial. Clin Rehabil. 2004;18(5):580-6.

19. de Weerd M, Greving JP, Hedblad B, Lorenz MW, Mathiesen EB, O'Leary DH, et al. Prediction of asymptomatic carotid artery stenosis in the general population: identification of high-risk groups. Stroke. 2014;45(8):2366-71.

20. Cohen DJ, Stolker JM, Wang K, et al. CREST investigators. Health-related quality of life after carotid stenting versus carotid endarterectomy: results from CREST (carotid revascularization endarterectomy versus stenting trial). J Am Coll Cardiol. 2011;58(15):1557-65. 
21. Stolker JM, Mahoney EM, Safley DM, et al. SAPPHIRE investigators. Healthrelated quality of life following carotid stenting versus endarterectomy: results from the SAPPHIRE (stenting and angioplasty with protection in patients at Hlgh risk for endarterectomy) trial. JACC Cardiovasc Interv. 2010; 3(5):515-23.

22. Vlajinac $\mathrm{H}$, Marinkovic J, Maksimovic $M$, et al. Health-related quality of life among patients with symptomatic carotid disease. Postgrad Med J. 2013; 89(1047):8-13.

23. Hye RJ, Mackey A, Hill MD, et al. Incidence, outcomes, and effect on quality of life of cranial nerve injury in the carotid revascularization endarterectomy versus stenting trial. J Vasc Surg. 2015;61(5):1208-14.

24. Shan L, Shan J, Saxena A, Robinson D. Quality of life and functional status after carotid revascularisation: a systematic review and meta-analysis. Eur J Vasc Endovasc Surg. 2015;49(6):634-45.

25. Middleton S, Donnelly N, Harris J, Lusby R, Ward J. Audit of long-term mortality and morbidity outcomes for carotid endarterectomy. Aust Health Rev. 2002;25:81-91.

26. The WHOQOL Group. Development of the world health organization WHOQOL-BREF quality of life assessment. Psychol Med. 1998;28(3):551-8.

27. Golicki D, Niewada M, Buczek J, et al. Validity of EQ-5D-5L in stroke. Qual Life Res. 2015;24(4):845-50.

28. World Health Organization. WHOQOL-BREF: introduction, administration, scoring and generic version of the assessment: field trial version. Geneva: WHO; 1996.

29. van Reenen M, Oppe M. EQ-5D-3L user Guide. EuroQol Res Found. 2015. p. $1-22$.

30. Warlow CP. Symptomatic patients: the European carotid surgery trial (ECST). J Mal Vasc. 1993;18(3):198-201.

31. Dimenas ES, Wiklund KW, Dahlof CG, et al. Differences in the subjective well-being and symptoms of normotensives, borderline hypertensives and hypertensives. J Hypertens. 1989;7:885-90

32. Wiklund I, Halling K, Ryden-Bergsten T, et al. Does lowering the blood pressure improve the mood? Quality-of-life results from the hypertension optimal treatment (HOT) study. Blood Press. 1997:6:357-64.

33. Lean ME1, Han TS, Seidell JC. Impairment of health and quality of life in people with large waist circumference. Lancet 1998;351(9106):853-856.

34. Han TS, Tijhuis MA, Lean ME, Seidell JC. Quality of life in relation to overweight and body fat distribution. Am J Public Health. 1998:88(12):1814-20.

35. Ford ES, Moriarty DG, Zack MM, Mokdad AH, Chapman DP. Self-reported body mass index and health-related quality of life: findings from the behavioral risk factor surveillance system. Obes Res. 2001;9(1):21-31.

36. LA T, Goins RT, Moore J, Campbell H. Loneliness, depression, social support, and quality of life in older chronically ill Appalachians. Aust J Psychol. 2012; 146(1-2):155-71.

37. Liu LJ, Guo Q. Loneliness and health-related quality of life for the empty nest elderly in the rural area of a mountainous county in China. Qual Life Res. 2007;16(8):1275-80.

38. Theeke L, Horstman P, Mallow J, et al. Quality of life and loneliness in stroke survivors living in Appalachia. J Neurosci Nurs. 2014;46(6):E3-15.

39. Choi-Kwon S, Choi JM, Kwon SU, et al. Factors that affect the quality of life at 3 years post-stroke. J Clin Neurol. 2006;2(1):34-41.

40. Widar M, Ahlström G, Ek AC. Health-related quality of life in persons with long-term pain after a stroke. J Clin Nurs. 2004 May;13(4):497-505.

41. Kong KH, Woon VC, Yang SY. Prevalence of chronic pain and its impact on health-related quality of life in stroke survivors. Arch Phys Med Rehabil. 2004;85(1):35-40.

42. Jönsson AC, Lindgren I, Hallström B, Norrving B, Lindgren A. Determinants of quality of life in stroke survivors and their informal caregivers. Stroke. 2005:36(4):803-8.

43. van Eeden $M$, van Heugten $C$, van Mastrigt GA, et al. The burden of stroke in the Netherlands: estimating quality of life and costs for 1 year poststroke. BMJ Open. 2015;5(11):e008220.

44. Mangen MJ, Bolkenbaas M, Huijts SM, van Werkhoven $\mathrm{CH}$, Bonten MJ, de Wit GA. Quality of life in community-dwelling Dutch elderly measured by EQ-5D-3L. Health Qual Life Outcomes. 2017;15(1):3.

45. Marmot M. Social determinants of health inequalities. Lancet. 2005; 365(9464):1099-104

46. Luengo-Fernandez R, Gray AM, Bull L, et al. Oxford vascular study. Quality of life after TIA and stroke: ten-year results of the Oxford vascular study. Neurology. 2013;81(18):1588-95.
47. Chang WH, Sohn MK, Lee J, et al. Impact of central facial palsy and dysarthria on quality of life in patients with stroke: the KOSCO study. NeuroRehabilitation. 2016;39(2):253-9.

48. Sand KM, Wilhelmsen $G$, Naess $H$, et al. Vision problems in ischaemic stroke patients: effects on life quality and disability. Eur J Neurol. 2016; 23(Suppl 1):1-7.

49. Min KB, Min JY. Health-related quality of life is associated with stroke deficits in older adults. Age Ageing. 2015;44(4):700-4

\section{Ready to submit your research? Choose BMC and benefit from:}

- fast, convenient online submission

- thorough peer review by experienced researchers in your field

- rapid publication on acceptance

- support for research data, including large and complex data types

- gold Open Access which fosters wider collaboration and increased citations

- maximum visibility for your research: over $100 \mathrm{M}$ website views per year

At BMC, research is always in progress.

Learn more biomedcentral.com/submissions 